\title{
COVID-19 - особенности течения у беременных женщин и детей младше 1 года
}

Мелехина Е.В., Николаева С.В., Усенко Д.В., Понежева Ж.Б., Музыка А.Д., Шабалина С.В., Хлыповка Ю.Н., Горелов А.В.

\section{Резюме}

Одним из вирусных агентов, вызывающих острые респираторные инфекции у человека, является коронавирус. Коронавирусы обладают широким тропизмом и могут поражать, помимо дыхательных путей, печень, почки, кишечник, нервную систему, сердце и глаза, поэтому клинические проявления коронавирусной инфекции разнообразны. Типичная коронавирусная инфекция протекает с поражением верхних и нижних отделов респираторного тракта и/или кишечными расстройствами. Коронавирусы поражают детей реже и менее серьезно, чем взрослых. Случаев смерти от SARS-CoV y детей нет; описаны случаи гибели младенцев от матерей, которые были инфицированы во время беременности MERS-CoV; смертность среди детей от SARS-CoV-2 единична. У новорожденных и детей первого года жизни болезнь регистрируется редко - в доступной литературе описаны единичные клинические случаи. Несмотря на то, что у детей COVID19 протекает легче, чем у взрослых, исследования показывают, что младенцы также подвержены новой коронавирусной инфекции. Для предотвращения распространения инфекции среди детей, рожденных от матерей с положительным тестом на SARS-CoV-2, и детей младше года, у которых матери болеют COVID-19, необходимо не только наблюдение за самими детьми, но и за их матерями, с проведением повторных тестирований на выделение PHК вируса SARS-CoV-2, поскольку исследования взрослых показали длительное выделение вируса с фекалиями даже после того, как орофарингеальные мазки оказались отрицательными.

Ключевые слова: COVID-19, SARS-COV-2, вирус, дети, течение, беременные женщины, новая коронавирусная инфекция.

Одним из вирусных агентов, вызывающих острые респираторные инфекции у человека, является коронавирус. Впервые он был выделен D. Tyrrell и M. Bynoe еще в 1965 г. от больного острым респираторным заболеванием, однако интенсивное изучение коронавирусов началось лишь в начале XXI веке с развитием технологически новых лабораторных методов исследования, таких как метод полимеразно-цепной реакции (ПЦР). В настоящее время достаточно хорошо исследованы следующие представители коронавирусов - HCoV-HKU1, HCoV-OC43 и HCoV-NL63. 
Клинические проявления коронавирусной инфекции разнообразны, так как коронавирусы обладают широким тропизмом и могут поражать, помимо дыхательных путей, печень, почки, кишечник, нервную систему, сердце и глаза. Типичная коронавирусная инфекция клинически проявляется поражением верхних и нижних отделов респираторного тракта и/или кишечными расстройствами.

Еще два новых штамма коронавирусов, способных вызывать заболевания у людей, открыты сравнительно недавно. К ним относятся коронавирус острого респираторного синдрома (SARS-CoV, впервые появился в 2002-2003 годах в провинции Гуандун (Китай)) и коронавирус ближневосточного респираторного синдрома (MERS-CoV, который проявился в Саудовской Аравии в 2012 году с аналогичными SARS клиническими симптомами, но с гораздо более высокой смертностью - около 35\%). Появление в 2019 г. коронавируса SARS-CoV-2, который вызывает новую коронавирусную инфекцию (COVID-19 - аббревиатура от англ. COrona VIrus Disease 2019) в Китае привело к пандемии, которая быстро распространилась и стала одной из самых значительных угроз общественному здоровью - из-за высокой частоты развития тяжелой пневмонии вплоть до летальных исходов.

Коронавирусы поражают детей реже и менее серьезно по сравнению со взрослыми. Случаев смерти от SARS-CoV у детей нет; описаны случаи гибели младенцев от матерей, которые были инфицированы во время беременности MERS-CoV. Смертность среди детей от SARS-CoV-2 единична - описаны 2 случая гибели детей в Китае (10-месячный младенец с инвагинацией и 14-летний подросток), 3 случаях в Европе (от 12 до 16 лет, один из детей имел иммунодефицитное состояние) и 1 случае гибели 6-недельного ребенка в США [1,2].

Первые исследования, опубликованные в начале 2020 г., показали, что у детей возможность заразиться SARS-CoV-2 столь же высока, как и у взрослых, но вероятность развития тяжелых форм меньше [3]. У детей и подростков, которые не имеют основных заболеваний (нарушение функции легких, иммуносупрессии и др.), риск развития тяжелых форм COVID-19 снижен по сравнению с другими возрастными группами [4]. Это может быть связано с тем, что дети имеют:

1) менее активный врожденный иммунный ответ (более энергичный иммунный ответ у взрослых может также объяснить гиперэргические иммунные реакции, которые приводят к развитию острого респираторного дистресс-синдрома);

2) более здоровые дыхательные пути, так как они не подвергались воздействию большого количества сигаретного дыма и загрязнения воздуха по сравнению со взрослыми; 
3) меньшее количество хронических соматических заболеваний.

\section{Особенности течения COVID-19 у беременных женщин и детей младше 1 года}

В настоящее время считается, что беременные женщины не подвергаются более высокому риску развития тяжелых заболеваний из-за COVID-19. Были обследованы 147 беременных женщин (64 подтвержденных, 82 подозрительных и 1 бессимптомная COVID19). Среди этих женщин $8 \%$ имели тяжелое заболевание, а $1 \%$ - критическое, что не превышает таковые значения среди популяции в целом. Кроме того, болезнь COVID-19, скорее всего, не влияет на течение беременности. Zhang I. et al. ретроспективно сравнили течение беременности и родов у 16 женщин с инфекцией SARS-CoV-2 и 45 беременных женщин, которые не были инфицированы [5]. Достоверных различий между группами беременных с COVID-19 и без него по возникновению патологии беременности (тяжелой преэклампсии, гестационного диабета, преждевременного разрыва плодных оболочек, дистресса плода, преждевременных родов, асфиксии новорожденных, процедуры наложения компрессионных швов) не было выявлено.

В настоящее время передача COVID-19 в родах не подтверждается. При обследовании 10 женщин с подтвержденной пневмонией, вызванной COVID-19, в Китае, когда РНК вируса в материале мазков из влагалища пациенток не обнаруживался [6]. 29летняя первородящая женщина (34 недели 2 дня беременности) была обследована с подозрением на инфекцию, вызванную SARS-CoV-2, после того, как у нее поднялась температура $37,9^{\circ} \mathrm{C}$, появилась заложенность носа, ухудшение самочувствия и общего состояния, которые постепенно прогрессировали и в итоге привели к возникновению дыхательных расстройств. При компьютерной томографии грудной клетки выявлен синдром «матового стекла» по периферии обоих легких. В материале мазка из носоглотки методом ПЦР была выявлена PHK SARS-CoV-2. Пациентка получила противовирусную, антибактериальную, кортикостероидную и кислородную терапию. Результаты 4 повторных тестов на PHK SARS-CoV-2 методом ПЦР были положительными, уровни IgGи IgM-антител к SARS-CoV-2 составили 107,89 и 279,72 AU/мл соответственно, при этом исследования вагинальных выделений пациентки методом ПЦР $\mathrm{c}$ обратной транскрипцией PHK SARS-CoV-2 обнаружена не была. Через 23 дня от начала болезни женщине произведено кесарево сечение, вес новорожденной девочки при рождении 3120 г, оценка по шкале Апгар 9/10 баллов, девочка не имела какой-либо симптоматики и была помещена на карантин в отделение интенсивной терапии новорожденных. В возрасте 2 ч уровень IgG к SARS-CoV-2 у ребенка составил 140,32 AU/Mл, IgM - 45,83 AU/мл. Цитокины были повышены (IL-6 28,26 пг/мл; IL-10 153,60 пг/мл), а также количество лейкоцитов $-18,08 \times 10^{9} / \mathrm{L}$. КТ грудной клетки была нормальной. Результаты 
5 тестов ПЦР (мазки из носоглотки, взятые в возрасте от 2 ч до 16 дней) были отрицательными. Уровни $\operatorname{IgM}(11,75 \mathrm{AU} / \mathrm{mL})$ и $\operatorname{IgG}(69,94 \mathrm{AU} / \mathrm{mL})$ оставались повышенными, девочка была выписана из стационара [7]. В данном случае повышенный уровень антител $\operatorname{IgM}$, определенный сразу после рождения, указывает на то, что новорожденная была заражена внутриутробно и ребенок потенциально мог подвергаться воздействию в течение 23 дней с момента установления у матери диагноза COVID-19 до родов. Результаты лабораторных исследований, показывающие повреждение печени, косвенно подтверждают возможность вертикальной передачи инфекции. Теоретически инфекция при родах не могла быть исключена, однако антитела IgM обычно не появляются от 3 до 7 дней после инфекции, а повышенный $\operatorname{IgM}$ у новорожденной был выявлен в образце крови, взятом через 2 ч после рождения. Кроме того, вагинальные выделения матери были отрицательными на SARS-CoV-2. Антитела IgG могут передаваться плоду через плаценту и появляться позже, чем IgM. Таким образом, повышенный уровень IgG может отражать материнскую или младенческую инфекцию. ПЦР-тестирование околоплодных вод или плаценты не проводилось.

У новорожденных и детей первого года жизни болезнь регистрируется редко - в доступной литературе описаны единичные клинические случаи. В Китае были описаны случаи неонатальной инфекции SARS-CoV-2, причем самый ранний из них был зарегистрирован через 30 ч после рождения [8], у другого новорожденного инфицирование было зафиксировано через 36 часов после родов [9]. Один младенец, у которого диагноз был установлен на 17-й день жизни, имел в анамнезе тесный контакт с матерью и няней, у которых была подтверждена инфекция SARS-CoV-2. У всех младенцев не было прямых доказательств вертикальной передачи инфекции, так как тестирование на вирус было отложено, а постнатальное инфицирование не было исключено [10].

В Китае с 8 декабря 2019 г. по 6 февраля 2020 г. наблюдали 9 госпитализированных младенцев в возрасте от 1 до 11 месяцев с диагнозом COVID-19. Из них у 4 была лихорадка, у 2 - легкие симптомы верхних дыхательных путей, у 1 симптомов заболевания не было, а у 2 - сведений о симптомах не сообщалось. Все 9 младенцев контактировали с членами своей семьи, инфицированными COVID-19. Bсе дети не нуждались в интенсивной терапии или искусственной вентиляции легких и не имели серьезных осложнений [8].

В рекомендациях CDC выделены 2 варианта клинических форм COVID-19 у новорожденных в зависимости от сроков выявления симптомов заболевания: раннее начало заболевания, отсроченное заболевание [11]. 
Раннее начало заболевания. Zeng et al. описывают 3 новорожденных с клинически манифестными формами COVID-19, рожденных от матерей, выделявших РНК SARS-CoV-2 в назофарингеальных мазках [12]. Двое из этих детей родились в срок, а один был недоношенным (рожден на 31 неделе). На рентгенограмме органов грудной клетки у всех 3 детей выявлены признаки пневмонии. У недоношенного ребенка был зарегистрирован респираторный дистресс-синдром и пневмония с признаками сепсиса и коагулопатии. Ему требовалась неинвазивная искусственная вентиляция легких и антибактериальная терапия. Другими клиническими признаками были лихорадка, тахипноэ, отказ от еды и цианоз. При лабораторных исследованиях крови выявлен лейкоцитоз, лимфопения, тромбоцитопения и повышение фракцию креатининкиназы-МБ. У всех 3 новорожденных PHK SARS-CoV-2 в материале мазков из носоглотки и анальных мазков выделялась до 6-го дня заболевания.

Отсроченное заболевание. У нескольких младенцев, рожденных от матерей, положительных на SARS-CoV-2, через 1-3 недели после рождения и/или выписки был описан поздний респираторный дистресс. Эти случаи могут представлять собой постнатально приобретенное заболевание и, как правило, являются легкими. После того, как ребенок выписан, существует вероятность не менее 15\% горизонтальной передачи SARS-CoV-2 от инфицированных членов семьи [1].

Заключение.

Несмотря на то, что у детей COVID-19 протекает легче, чем у взрослых, исследования показывают, что младенцы также подвержены новой коронавирусной инфекции [13, 14]. Для предотвращения распространения инфекции среди детей, рожденных от матерей с положительным тестом на SARS-CoV-2, и детей младше года, у которых матери болеют COVID-19, необходимо не только наблюдение за самими детьми, но и за их матерями, с проведением повторных тестирований на выделение РНК вируса SARS-CoV-2, поскольку исследования взрослых показали длительное выделение вируса с фекалиями даже после того, как орофарингеальные мазки оказались отрицательными [15].

Литература.

1. Lu X, Zhang L, Du H, Zhang J, Li YY, Qu J, et al. SARS-CoV-2 Infection in Children. N Engl J Med. 2020 Mar 18. DOI: 10.1056/NEJMc2005073.

2. Zimmermann P, Curtis N. Coronavirus Infections in Children Including COVID-19. Pediatr Infect Dis J. 2020; March 12, Volume Online First - Issue. DOI: 10.1097/INF.0000000000002660.

3. Bi Q, Wu Y, Mei S, et al. Epidemiology and transmission of COVID-19 in Shenzhen 
China: analysis of 391 cases and 1,286 of their close contacts. medRxiv 2020. Доступ 4 марта, 2020. Адрес: https://doi.org/10.1101/2020.03.03.20028423.

4. Brodin P. Why is COVID-19 so mild in children? Acta Paediatr. 2020 Mar 25. DOI: 10.1111/apa.15271 Ludvigsson JF. Systematic review of COVID-19 in children shows milder cases and a better prognosis than adults. Acta Paediatr. 2020 Mar 23. DOI: 10.1111/apa.15270.

5. Zhang I, Jiang Y, Wei M, Cheng BH, Zhou XC, Li J, et al. [Analysis of the Pregnancy Outcomes in Pregnant Women With COVID-19 in Hubei Province]. Zhonghua $\mathrm{Fu}$ Chan Ke Za Zhi. 2020 Mar 7;55(0):E009. doi: 10.3760/cma.j.cn112141-20200218-00111.

6. Qiu L, Liu X, Xiao M, Xie J, Cao W, Liu Z, et al. SARS-CoV-2 is not detectable in the vaginal fluid of women with severe COVID-19 infection. Clin Infect Dis. 2020;Apr 2: pii: ciaa375. DOI: 10.1093/cid/ciaa375.

7. Dong L, Tian J, He S, Zhu C, Wang J, Liu C, Yang J. Possible Vertical Transmission of SARS-CoV-2 From an Infected Mother to Her Newborn. JAMA. JAMA. 2020 Mar 26. DOI: 10.1001/jama.2020.4621.

8. Hong H, Wang Y, Chung HT, Chen CJ. Clinical characteristics of novel coronavirus disease 2019 (COVID-19) in newborns, infants and children. Pediatr Neonatol. 2020 Apr;61(2):131-132. DOI: 10.1016/j.pedneo.2020.03.001.

9. Schwartz DA. COVID-19, SARS-CoV-2 and pregnancy: Does the past predict the present? Contagion Live. [доступ 28 февраля 2020] Адрес: https://www.contagionlive.com/news/covid19-sarscov2-and-pregnancy-does-thepast-predict-the-present.

10. Qiao J. What are the risks of COVID-19 infection in pregnant women? Lancet. 2020 Mar 7;395(10226):760-762. DOI: 10.1016/S0140-6736(20)30365-2.

11. Chandrasekharan P, Vento M, Trevisanuto D, Partridge E, Underwood MA, Wiedeman J, et al. Neonatal Resuscitation and Postresuscitation Care of Infants Born to Mothers with Suspected or Confirmed SARS-CoV-2 Infection. Am J Perinatol. 2020 Apr 8. DOI: 10.1055/s-0040-1709688

12. Zeng L, Xia S, Yuan W, Yan K, Xiao F, Shao J, Zhou W. Neonatal early-onset infection with SARS-CoV-2 in 33 neonates born to mothers with COVID-19 in Wuhan, China. JAMA Pediatr. 2020 Mar 26. DOI: 10.1001/jamapediatrics.2020.0878

13. Dong Y, Mo X, Hu Y, et al. Epidemiological characteristics of 2143 pediatric patients with 2019 coronavirus disease in China. Pediatrics. 2020; DOI: 10.1542/peds.20200702 https://pediatrics.aappublications.org/content/early/2020/03/16/peds.2020- 
0702.long

14. Cruz AT, Zeichner SL. COVID-19 in Children: Initial Characterization of the Pediatric Disease. Pediatrics. 2020;e20200834. DOI: 10.1542/peds.2020-0834.

15. Pan Y, Zhang D, Yang P, Poon LLM, Wang Q. Viral load of SARS-CoV-2 in clinical samples. Lancet Infect Dis. 2020 Apr;20(4):411-412. DOI: 10.1016/S14733099(20)30113-4.

Сведения об авторах:

Мелехина Елена Валериевна (Elena V. Melekhina), доктор медицинских наук, доцент по специальности педиатрия, ведущий научный сотрудник клинического отдела инфекционной патологии ЦНИИ Эпидемиологии Роспотребнадзора. Адрес: 111123, г. Москва, ул. Новогиреевская д. За. Телефон: (495) 6721158, электронная почта e.melekhina@mail.ru

orcid.org/0000-0002-9238-9302

Николаева Светлана Викторовна, кандидат медицинских наук, старший научный сотрудник клинического отдела инфекционной патологии ЦНИИ Эпидемиологии Роспотребнадзора. Адрес: 111123, г. Москва, ул. Новогиреевская д. За. Телефон: (495) 6721158, электронная почта nikolaeva008@list.ru

Телефон: (495) 6721158

Горелов Александр Васильевич (Alexandr V. Gorelov) - член-корреспондент РАН, доктор медицинских наук, профессор; заместитель директора по научной работе ФБУН «Центральный НИИ эпидемиологии» Роспотребнадзора; профессор кафедры детских болезней ФГАОУ ВО Первый МГМУ им. И.М. Сеченова Минздрава России (Сеченовский Университет). Адрес: 111123, г. Москва, ул. Новогиреевская д. За. Телефон: (495) 6721158, e-mail: crie@pcr.ru

orcid.org/0000-0001-9257-0171

Музыка Анна Драгиевна (Anna D. Muzyka)- к.м.н., научный сотрудник клинического отдела инфекционной патологии ЦНИИ эпидемиологии Роспотребнадзора; Адрес: 111123, г. Москва, ул. Новогиреевская д. За. Телефон: (495) 6721158, e-mail: nikolitch-anna@yandex.ru; 
Понежева Жанна Бетовна - доктор медицинских наук, заведующая клиническим отделом инфекционной патологии ФБУН «Центральный НИИ эпидемиологии» Роспотребнадзора, Москва, Россия; e-mail: doktorim@mail.ru; ORCID: https://orcid.org/0000-0002-6539-4878

Усенко Денис Валериевич, доктор медицинских наук, ведущий научный сотрудник клинического отдела инфекционной патологии ФБУН «Центральный НИИ эпидемиологии» Роспотребнадзора; Москва, Россия. Адрес: 111123, г. Москва, ул. Новогиреевская д. 3а. Телефон: +7(495) 6721158, электронная почта dusenko@rambler.ru ORCID: https://orcid.org/0000-0001-5232-7337

Хлыповка Юлия Николаевна, кандидат медицинских наук, младший научный сотрудник клинического отдела инфекционной патологии ЦНИИ Эпидемиологии Роспотребнадзора. Адрес: 111123, г. Москва, ул. Новогиреевская д. 3а. Телефон: (495) 6721158, электронная почта crie@ pcr.ru

Orcid.org/ 0000-0003-4821-676X

Шабалина Светлана Васильевна, доктор медицинских наук, профессор, ведущий научный сотрудник клинического отдела инфекционной патологии ЦНИИ Эпидемиологии Роспотребнадзора. Адрес: 111123, г. Москва, ул. Новогиреевская д. 3а. Телефон: (495) 6721158, электронная почта 